\title{
Efficacy, precision, and safety of micro-monovision laser-assisted in situ keratomileusis as a treatment for presbyopia in hyperopic patients
}

\section{Eficacia, precisión y seguridad del LASIK con técnica de micromonovisión para el tratamiento de la presbicia en pacientes hipermétropes}

\author{
Alejandro Tamez-Peña*, Samantha E. Andrade-Leal, Manuel A. De Alba Castilla, Christian Cadena-Garza, \\ and Jorge E. Valdez-García
}

Institute of Ophthalmology and Visual Sciences, Escuela de Medicina del Tecnológico de Monterrey, Monterrey, Nuevo León, Mexico

\begin{abstract}
Purpose: The purpose of the study was to evaluate the outcomes of micro-monovision laser-assisted in situ keratomileusis (LASIK) in hyperopic patients with presbyopia. Methods: Retrospective case series that identified hyperopic patients that underwent micro-monovision LASIK in the Visual Science Institute at hospital Zambrano Hellion from November 2018 to May 2019. A Technolas 217c (Bausch and Lomb) excimer laser was used. The target refraction for the dominant eye was Plano and for the non-dominant eye, between -0.75 and -1.50 . Patients were followed-up for 6 months. Results: Sixty eyes of 30 consecutive patients were evaluated. Mean age was 51.63 years $( \pm 4.55)$. Average refraction in the non-dominant eye was -1.34 \pm 0.3. Eighty-seven percent of the patients achieved a 20/20 uncorrected binocular distance visual acuity and $100 \%$ achieved $20 / 40$ or better. Ninety-seven percent achieved an uncorrected binocular near visual acuity of J2 or better and $100 \%$ of $\mathrm{J} 4$ or better. No eyes showed loss of lines with best spectacle-corrected visual acuity. We performed retreatment in one eye (2.9\%). Conclusions: Micro-monovision LASIK is an effective, precise, and safe treatment option for presbyopia in hyperopic patients.
\end{abstract}

Key words: Refractive surgery. Hyperopia. Laser-assisted in Situ Keratomileusis. Monovision. Presbyopia.

\section{Resumen}

Objetivo: Evaluar los resultados obtenidos con la técnica de queratomileusis in situ asistida con láser (LASIK, Laser Assisted in Situ Keratomileusis) con micromonovisión en pacientes présbitas hipermétropes. Método: Estudio retrospectivo, serie de casos de pacientes hipermétropes operados de LASIK con la técnica de micromonovisión en el Instituto de Ciencias Visuales del Hospital Zambrano Hellion, de noviembre de 2018 a mayo de 2019. Se utilizó un excimer Technolas 217c (Bausch and Lomb). La refracción meta del ojo dominante fue de plano para emetropía, y la del ojo no dominante fue de -0.75 a -1.50. Se realizó un seguimiento de 6 meses. Resultados: Fueron evaluados 60 ojos de 30 pacientes consecutivos. La edad promedio era de 51.63 años $( \pm 4.55)$. El promedio de miopización para el ojo no dominante fue de $-1.34 \pm 0.3$. El 87\% obtuvo una agudeza visual binocular sin corrección a distancia de 20/20, y el 100\% de 20/40 o mejor. El 97\% alcanzaron

Correspondence:

*Alejandro Tamez-Peña

Av. Morones Prieto, 3000, piso 6 \#602

Col. Los doctores

Date of reception: 16-06-2019

Date of acceptance: 09-06-2020

DOI: 10.24875/RMOE.M20000145
Available online: 11-01-2021 Rev Mex Oftalmol (Eng). 2021;95(1):15-19 www.rmo.com.mx 
una agudeza visual binocular cercana sin corrección J2, y el 100\% J4 o mejor. Ningún ojo presentó pérdidas en líneas de visión mejor corregida. Se realizó un retratamiento en un ojo (2.9\%). Conclusiones: EI LASIK con técnica de micromonovisión demostró ser una alternativa efectiva, precisa y segura para el tratamiento de la presbicia en pacientes hipermétropes.

Palabras clave: Cirugía refractiva. Hipermetropía. LASIK. Monovisión. Presbyopia.

\section{Introduction}

Presbyopia is an age-related condition characterized by a decrease in the eye's ability to focus on nearby objects. It is attributed to the loss of elasticity of the lens and is accompanied by changes in the contractile force of the ciliary muscle and the curvature of the lens ${ }^{1}$.

At present, presbyopia is a new great challenge to be solved with refractive surgery. Year after year, new surgical techniques and intraocular lenses appear that seek to become the answer to this problem.

To date, there are two approaches for the treatment of presbyopia: the accommodative and the pseudo-accommodative. The accommodative approach aims to reverse presbyopia by restoring the patient's natural accommodation through an intraocular lens that moves inside the capsular bag. The pseudo-accommodative approach is based on increasing the depth of focus of the patient through non-accommodative factors ${ }^{2}$.

The concept of monovision is a pseudo-accommodative approach and was used first with contact lenses and was later incorporated into refractive surgery due to its success. In this technique, the dominant eye is corrected for distance with target refraction for emmetropia and the non-dominant eye for near with target refraction ranging from -1.50 to $-2.50^{3-6}$.

Reinstein et al. ${ }^{7-9}$ coined the concept of micro-monovision, in which the target refraction in the non-dominant eye ranges from -1.00 to -1.50 to increase the depth of focus of the non-dominant eye and try to avoid the adverse effects of a high anisometropia. Monovision and pseudophakic micro-monovision have been used for several years as an alternative to multifocal and extended vision lenses to acquire spectacle independence ${ }^{5,10-12}$.

The objective of this study is to present the results obtained with the micro-monovision technique in hyperopic presbyopic patients operated with the laser-assisted in situ keratomileusis (LASIK) technique.

\section{Methods}

Longitudinal, descriptive, and retrospective study that evaluated LASIK cases operated with the micro-monovision technique at the Institute of Visual Sciences of the Zambrano Hellion Hospital from November 2018 to
May 2019. The inclusion criteria were age between 40 and 65 years, meeting the safety parameters for LASIK surgery, and having undergone micro-monovision treatment in the non-dominant eye $(-0.75--1.50)$. Patients with previous ocular pathologies and surgeries were excluded from the study.

Pre-operative examination included a detailed evaluation with manifest and cycloplegic refraction, distance-uncorrected visual acuity (DUVE), distance corrected visual acuity, near UCVA, near CVA, biomicroscopy, tonometry, and fundoscopy under cycloplegia. In this examination, we evaluated patient's expectations regarding spectacle independence and micro-monovision was addressed in detail. All patients were told that surgery would give them a percentage of spectacle independence but still require them for certain near activities. They were also told that if they were not satisfied with the result, the micro-monovision eye could be reoperated to change it to target refraction for emmetropia at no cost for the patient.

All patients had a corneal topography (Orbscan) to rule out corneal pathologies and evaluate pachymetry.

Visual acuity was measured at a distance with the Snellen chart and up close with a Rosenbaum chart at $40 \mathrm{~cm}$. Ocular dominance was assessed using the hole-in-hand technique.

All the patients were operated on by the same surgeon (JV) at the refractive surgery center of the Zambrano Hellion Hospital of the Tecnológico de Monterrey. A 120-micron flap created with a Hansatome XP microkeratome (Bausch and Lomb) was used. For ablation, a Technolas 217c (Bausch and Lomb) excimer was used. The optical zone was $6 \mathrm{~mm}$, with a transition zone of $8 \mathrm{~mm}$. The target refraction of the dominant eye was for emmetropia and that of the non-dominant eye was for -0.75--1.50. The age of the patient did not influence the selection of the refraction in the non-dominant eye. In all cases, the patient's binocular vision was evaluated in the phoropter with refraction for emmetropia in the dominant eye and 1.50 in the non-dominant eye. In the event that the patient showed dissatisfaction with their far binocular vision, the addition was decreased at intervals of 0.25 until reaching 0.75 .

The patients received treatment with a combined antibiotic and topical steroid for 9 days and with artificial 
tears for 1 month. Postoperative follow-up was at 1 day, 1 week, 1 month, 3 months, and 6 months. At each visit, refraction, distance UCVA, distance CVA, and near UCVA were assessed, and biomicroscopy was performed.

Visual acuity was converted to LogMAR for statistical analysis purposes; this was done with the Microsoft Office Excel 2011 v14.0 and SPSS v22.0 programs. The paired Student's t-test was used to determine the difference between pre-operative distance UCVA and post-operative distance UCVA. We also evaluated the difference between pre-operative near UCVA and post-operative near UCVA. Statistical significance was determined with a $p<0.05$.

\section{Results}

Sixty eyes of 30 consecutive patients ( 16 women and 14 men) who underwent LASIK with the micro-monovision technique were evaluated.

Average age was of 51.63 years $( \pm 4.55)$. Twenty-four $(80 \%)$ patients had hyperopic astigmatism and $6(20 \%)$ had simple hyperopia. Regarding ocular dominance, $50 \%$ was in the right eye and $50 \%$ in the left eye. The average myopization for the non-dominant eye was $-1.34 \pm 0.3$.

\section{Efficacy}

At 6 months, binocular distance UCVA was 20/20 or better in $87 \%$ of the patients, and $20 / 40$ or better in $100 \%$ (Fig. 1A). Ninety-seven percent of the patients had a near binocular UCVA of J2 or better and $100 \%$ of $\mathrm{J} 4$ or better (Fig. 1B).

Pre-operative logMAR binocular distance UCVA was $0.22 \pm 0.2$, and post-operative binocular distance UCVA was $0.02 \pm 0.06$. Pre-operative binocular near UCVA was $0.73 \pm 0.18$, and post-operative binocular near UCVA was $0.05 \pm 0.06$.

\section{Safety}

No loss of Snellen lines was observed for best-corrected visual acuity (Fig. 1C). There were no reports of intra-operative or post-operative complications.

\section{Precision}

Figure 1D presents a scatter plot of the planned versus postoperative spherical equivalent after LASIK surgery. Figure $1 \mathrm{E}$ shows a histogram of the precision of the spherical equivalent obtained. Six months after the
LASIK, $72 \%$ were within $\pm 0.50 \mathrm{D}$, and $100 \%$ were within $\pm 1.00 \mathrm{D}$. Three percent of the eyes were undercorrected by $\geq 1.00 \mathrm{D}$.

\section{Cylinder}

Forty-four percent of the operated eyes had a pre-operative cylinder of $\leq 0.50 \mathrm{D}$ and $72 \%$ had $\leq 1.00 \mathrm{D}$. Fifty-three percent of the operated eyes had residual astigmatism of $\leq 0.50 \mathrm{D}$, and in $78 \%$, it was $\leq 1.00 \mathrm{D}$ (Fig. 1F).

\section{Retreatments}

One patient $(2.9 \%)$ requested to reverse the micro-monovision in the non-dominant eye since he was not satisfied with his binocular distance UCVA (20/40). The rest of the patients (97.1\%) were satisfied with the results obtained.

\section{Discussion}

In this retrospective study, the safety, efficacy, and precision of micro-monovision using LASIK surgery were analyzed in presbyopic patients with hyperopia. We expected that this technique would improve binocular UCVA, with the dominant eye being responsible for an improvement in distance vision and the non-dominant eye for near vision.

Eighty-seven percent of the patients obtained a binocular distance UCVA of 20/20 or better. This differs slightly from that found by Reinstein et al. ${ }^{7}$, who reported that $95 \%$ achieved 20/20 or better in post-operative binocular UCVA. Schallhorn et al. ${ }^{13}$ reported that only $77.5 \%$ of the patients achieved $20 / 20$ or better, although their study was about monovision with target refraction of up to -2.00 .

Regarding the near vision, $97 \%$ of the patients achieved J2 or better and $100 \% \mathrm{~J} 4$ or better. These results were better than those of Reinstein et al. ${ }^{7}$ since in their study, $81 \%$ achieved J2 or better and $100 \% \mathrm{~J} 5$ or better. Schallhorn et al. ${ }^{13}$ reported that $95.6 \%$ of their patients obtained $\mathrm{J} 5$ or better.

Statistical significance was observed when comparing pre-operative binocular distance UCVA $(0.22[ \pm 0.2])$ with post-operative binocular distance UCVA (0.02 [ \pm $0.06]$ ) ( $p$ <.001), as well as when comparing pre-operative binocular near UCVA $(0.73[ \pm 0.18])$ with post-operative binocular near UCVA $(0.05[ \pm 0.06])(p<0.001$, paired Student's t-test).

The good results in near vision in patients treated with LASIK and the micro-monovision technique for hyperopia are probably due to the increase in the 


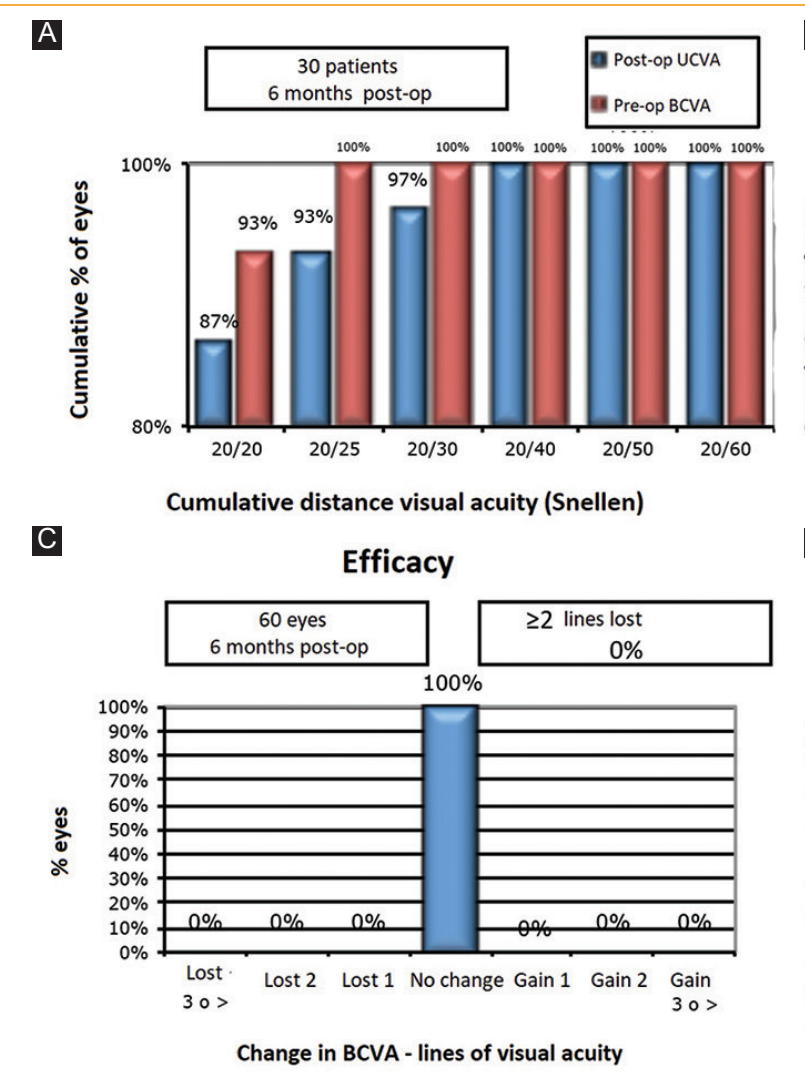

$\mathbf{E}$

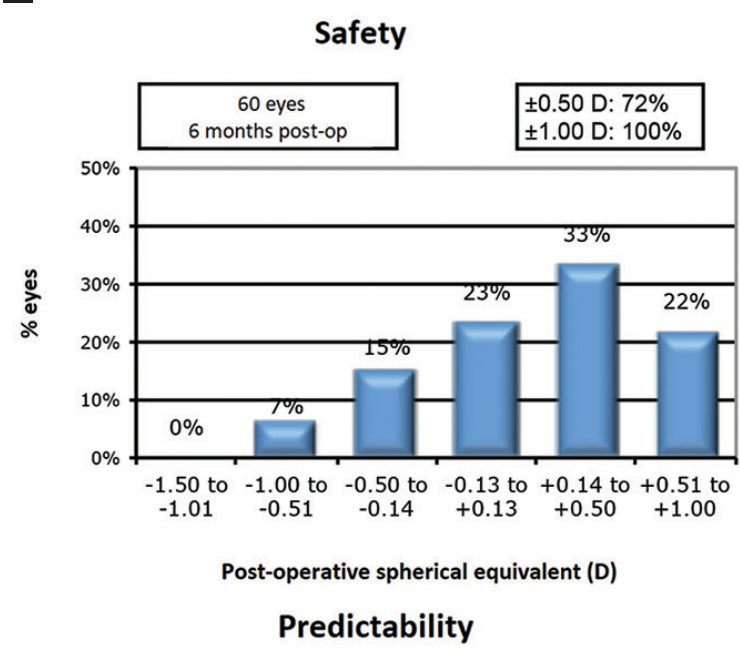

B
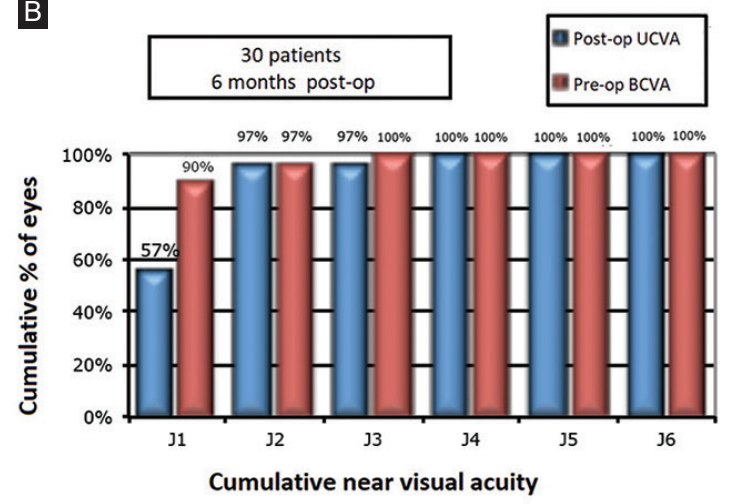

D

Efficacy

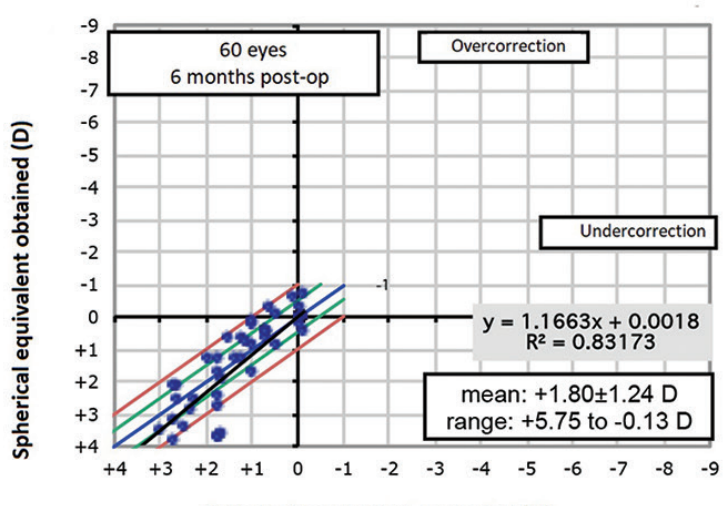

$\mathbf{F}$

Spherical equivalent corrected (D)

Predictability

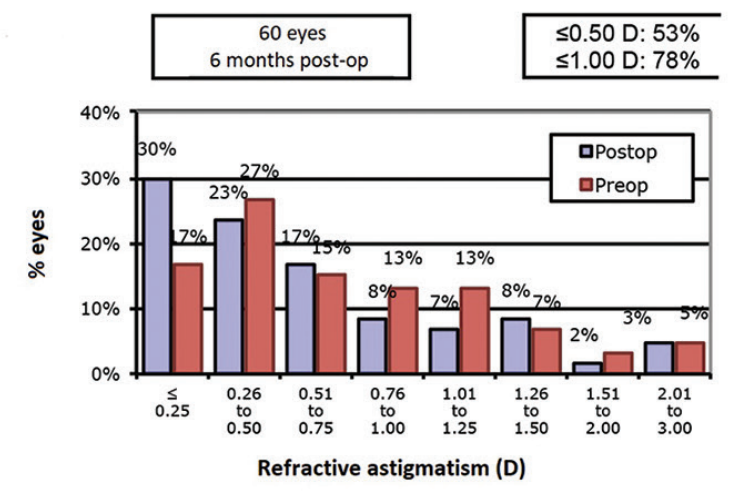

Residual astigmatism

Figure 1. A: Distance vision efficacy. B: Near vision efficacy. C: Safety D and E: Predictability. F: Residual astigmatism.

prolate shape of the cornea, and with this, the increase in negative spherical aberration and depth of focus.

The treatment was shown to be safe since there was no loss of lines of best-corrected distance visual acuity. Reinstein et al..$^{7}$ and Schallhorn et al. ${ }^{13}$ obtained similar results, in which no eye had a loss of more than two lines of visual acuity.
Although no postoperative complications were recorded, it is well known that performing photorefractive surgery in ages over 40 years can cause dry eye, for which the evaluation of the tear film is essential in this age group, as in any patient candidate for photorefractive surgery ${ }^{14}$.

Single retreatment $(2.9 \%)$ was performed on a 48-year-old hyperopic patient because she was not 
satisfied with her binocular distance vision, so a correction was made in her non-dominant eye and the micro-monovision was eliminated.

This study, being retrospective, has several limitations. We would have liked to know the pre-operative and post-operative contrast sensitivity, as well as the intermediate vision before and after surgery, and to be able to evaluate in some objective way the satisfaction of the patients and the degree of spectacle independence.

\section{Conclusion}

As the search for the perfect treatment for presbyopia continues, LASIK micro-monovision technique has proven to be an effective, accurate, and safe option.

\section{Funding}

The authors received no funding for this work.

\section{Conflicts of interest}

The authors declare no conflicts of interest.

\section{Ethical disclosures}

Protection of human and animal subjects. The author declares that no experiments have been conducted on humans or animals for this research.

Confidentiality of data. The author states that he has followed the guidelines of his institution on the publication of patient data.

Right to privacy and informed consent. The author has obtained the informed consent of the patients and/ or subjects referred to in the article. The corresponding author is in possession of this document.

\section{References}

1. Luger MH, McAlinden C, Buckhurst PJ, Wolffsohn JS, Verma S, Arba Mosquera S. Presbyopic LASIK using hybrid bi-aspheric micro-monovision ablation profile for presbyopic corneal treatments. Am J Ophthalmol. 2015;160:493-505

2. Vastardis I, Pajic-Eggspühler B, Müller J, Cvejic Z, Pajic B. Femtosecond laser-assisted in situ keratomileusis multifocal ablation profile using a mini-monovision approach for presbyopic patients with hyperopia. Clin Ophthalmol. 2016;10:1245-56.

3. Smith CE, Allison RS, Wilkinson F, Wilcox LM. Monovision: consequences for depth perception from large disparities. Exp Eye Res. 2019;183: 62-7.

4. Labiris G, Giarmoukakis A, Patsiamanidi M, Papadopoulos Z Kozobolis VP. Mini-monovision versus multifocal intraocular lens implantation. J Cataract Refract Surg. 2015;41:53-7.

5. Zettl S, Reiß S, Terwee T, Guthoff RF, Beck R, Stachs O. Effect of pseudophacic mini-monovision as an option for independence of spectacles in everyday life. Klin Monbl Augenheilkd. 2014;231:1196-202.

6. Goldberg DG, Goldberg MH, Shah R, Meagher JN, Ailani H. Pseudophakic mini-monovision: high patient satisfaction, reduced spectacle dependence, and low cost. BMC Ophthalmol. 2018;18:293.

7. Reinstein DZ, Couch DG, Archer TJ. LASIK for hyperopic astigmatism and presbyopia using micro-monovision with the Carl Zeiss Meditec MEL80 platform. J Refract Surg. 2009;25:37-58.

8. Reinstein DZ, Archer TJ, Gobbe M. LASIK for myopic astigmatism and presbyopia using non-linear aspheric micro-monovision with the Carl Zeiss Meditec MEL 80 Platform. J Refract Surg. 2011;27:23-37.

9. Reinstein DZ, Carp GI, Archer TJ, Gobbe M. LASIK for presbyopia correction in emmetropic patients using aspheric ablation profiles and a micro-monovision protocol with the Carl Zeiss Meditec MEL 80 and VisuMax. J Refract Surg. 2012;28:531-41.

10. Labiris G, Giarmoukakis A, Patsiamanidi M, Papadopoulos Z, Kozobolis VP. Mini-monovision versus multifocal intraocular lens implantation. J Cataract Refract Surg. 2015;41:53-7.

11. Goldberg DG, Goldberg MH, Shah R, Meagher JN, Ailani H. Pseudophakic mini-monovision: high patient satisfaction, reduced spectacle dependence, and low cost. BMC Ophthalmol. 2018;18:293.

12. Wilkins MR, Allan BD, Rubin GS, Findl O, Hollick EJ, Bunce C et al Moorfields IOL Study Group. Randomized trial of multifocal intraocular lenses versus monovision after bilateral cataract surgery. Ophthalmology. 2013;120:2449-55.e1.

13. Schallhorn SC, Teenan D, Venter JA, Schallhorn JM, Hettinger KA Hannan SJ, et al. Monovision LASIK versus presbyopia-correcting IOLs: comparison of clinical and patient-reported outcomes. J Refract Surg. 2017;33:749-58.

14. Mahrous A, Ciralsky JB, Lai EC. Revisiting monovision for presbyopia. Curr Opin Ophthalmol. 2018;29:313-7. 